\title{
陠地植被生态水文过程前沿进展: 从植物叶片到流域
}

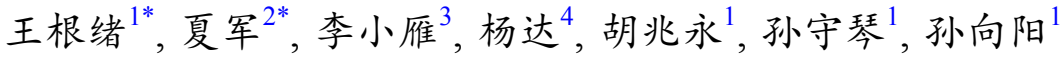 \\ 1. 四川大学水利水电学院, 水力学与山区河流开发保护国家重点实验室, 成都 610065; \\ 2. 武汉大学水资源与水电工程科学国家重点实验室, 武汉 430072; \\ 3. 北京师范大学地理科学学部自然资源学院, 北京 100875 ; \\ 4. 中国科学院西双版纳热带植物园, 㔚腊 666303 \\ * 联系人, E-mail: wanggx@scu.edu.cn; xiajun666@whu.edu.cn \\ 2020-10-19 收稿, 2020-12-18 修回, 2020-12-21 接受, 2020-12-23 网络版发表 \\ 国家自然科学基金(41790431)和中国科学院战略性先导科技专项(XDA23090201)资助
}

摘要 陆地植被生态水文过程是生态学、水文学和全球变化研究关注的前沿领域, 更是生态水文学的关键理论基 础之一。近年来围绕植被生态与水相互作用的研究范畴涵盖了从植物细胞到大陆尺度的几乎所有空间尺度, 在不 同尺度上分别在生态学和水文学各自视角取得了较大进展. 但从生态水文学交叉学科角度, 迫切需要整合生态学 与水文学多尺度相关研究进展, 系统性地归纳和总结跨尺度理论和方法进展, 梳理理论前沿热点问题. 为此, 本文 从近年来关于陆地植被生态水文过程与模拟研究进展中, 系统提炼和总结了以植物水分利用与调控机制、碳氮水 耦合循环过程与模拟、水循环关键过程的生态作用、植被生态作用下的径流形成与变化、植被生态水循环变化 对大气降水过程的反馈影响等为主要研究热点的理论前沿方向, 系统总结了这五方面在不同尺度及跨尺度方面所 取得的主要进展, 特别关注了基于过程机理的定量模型方面的发展状态. 基于这些前沿热点面临的挑战性难题, 提 出了未来需要重点关注的核心问题，包括探索植物水分利用与调控的多尺度关联机制、发展基于过程机制的碳氮 水耦合循环精准模拟方法、径流形成与动态变化的生态因素甄别与定量刻画等. 对深入理解生态水文学国际前沿 发展趋势, 引导我国生态水文学学科的发展方向等有参考意义.

关键词陆地植被生态水文过程, 多尺度, 植物水分利用与调控, 碳氮水耦合

生态与水文的相互作用关系研究，包括植物个体 的水分行为(碳水耦合过程、水分利用策略)、群落尺 度的水分分配与利用、生态系统尺度的碳水过程与水 循环作用关系、景观或流域尺度的水文过程影响等, 不仅是生态学领域的前沿核心研究内容, 也是水文学 领域的前沿科学问题, 更是生态水文学这一新型交叉 学科发展的基础 ${ }^{[1,2]}$. 自从国际地圈-生物圈计划(IGBP) 在 20 世纪90年代初期在全球开展水循环的生物学方面 (BAHC)研究计划以来, 经过 10 多年的大量观测研究, 人们认识到对水循环生物圈方面作用机理的深人理解
是水文循环过程准确认知的关键，一切基于物理机制 的水文模型面临的最大挑战也在于对水循环生物圈方 面过程的定量刻画 ${ }^{[3,4]}$. 明确区域水循环和其他反馈与 耦合因素(如植被和碳氮循环)的相互作用机制, 以修正 水文模型中对水循环过程驱动机制的描述和驱动要素 的进一步完善, 这是未来水文模型发展中需要解决的 重要问题之一 ${ }^{[5,6]}$. 随着全球变化研究的不断深人，人 们逐渐发现陆面-植被-水-大气系统中的反馈互为相关, 不仅决定流域、区域能水平衡，还与全球气候系统密 切关联, 是全球气候变化中不可忽略的重要影响因素. 
因此，了解生态学、水文学和其他领域(如水土保持学 等)对生态-水相互关系研究的进展和面临的挑战, 有助 于在生态学、水文学、生态水文学以及全球变化研究 中探索各自相关前沿问题的解决方案.

陆地植被生态水文过程是生态与水文相互作用关 系研究的核心, 研究对象涵盖了从植物叶片的细胞(或 分子)、植株个体、植被群落、生态系统、流域、区 域、大陆以及全球等几乎全部空间尺度 ${ }^{[7,8]}$. 不同尺度 开展的植被生态水文过程研究所针对的问题有所不 同，如细胞尺度关注植物代谢过程的各种生理生化反 应，叶片尺度则更集中于碳氮水耦合调控机制与最优 气孔导度模式, 而在流域和大陆尺度主要关注土地利 用/覆盖变化对径流形成等水文过程的影响．尽管有大 量研究针对某一特定尺度的核心生态水文问题开展了 专门的研究进展综述, 如叶片光合作用与气孔导度模 型 ${ }^{[9]}$ 、林冠截留模型 ${ }^{[10]}$ 以及流域土地利用与覆盖变化 的径流效应 ${ }^{[11]}$ 等, 但现阶段很少有研究对不同尺度开 展的有关植被生态水文过程的研究进展进行系统性地 综合归纳. 生态水文学在整合生态学和水文学相关理 论过程中，特别强调跨尺度理论和方法的集成与发展， 因此, 更加重视基于前沿理论问题导向的多尺度研究 进展的综合 ${ }^{[2,12,13]}$. 然而, 目前几乎没有针对陆地植被 生态水文过程前沿理论问题研究的跨尺度进展综述, 限制了我们对生态水文学理论前沿进展的系统认知. 为此, 本文在查阅最近10 15年相关研究文献基础上, 重点开展三方面的总结和分析工作: (1) 梳理陆地植被 生态水文过程研究的主要前沿热点及其在不同尺度上 的主要研究进展, 明确不同前沿热点面临亟待解决的 理论问题与挑战; (2) 从跨尺度综合集成角度, 系统归 纳不同前沿领域在多尺度拓展方面的主要进展，特别 关注跨尺度定量分析模型的发展状态; (3) 展望陆地植 被生态-水文相互关系及其影响研究的未来重点关注 方向.

\section{1 陆地植被生态水文过程研究热点问题}

生态系统变化对水文过程的影响、水文过程变化 对生态系统的作用、水文-生态-社会耦合与流域水管 理以及陆-气耦合与反馈中的生态水文过程, 是生态水 文学的主要研究内容 ${ }^{[2]}$. 其中生态系统变化对水文过 程的影响、陆-气耦合与反馈中的生态水文过程两大 研究领域广泛涉及陆地植被生态水文过程的相关科学 问题 ${ }^{[1,8,13]}$. 围绕这两个研究领域, 从生态水文学及其母
学科生态学和水文学范畴内, 通过收集和分析近 10 15 年相关研究文献，归纳整理出目前在陆地植被生态水 文过程领域主要关注的五方面热点前沿问题：植物水 分利用与调控、碳氮水耦合循环过程、水文循环关键 过程、径流形成与变化以及陆-气作用的降水反馈效 应等(图1). 其中, 植物水分利用策略与调控方面包含了 有关植被生态-水文相互关系的多个研究方向，可进一 步归纳为: 植物水力调控机制与水分利用权衡、植物 水分利用策略与根系水力再分配机制以及最优冠层导 度与模拟 3 个主要方向; 碳氮水耦合循环过程方面, 重 点关注植物叶片和冠层尺度碳氮水耦合循环机制、基 于过程机制的定量模型发展以及基于模型的大尺度碳 氮水循环模拟; 水循环关键过程方面, 现有研究在植被 的降水再分配过程、土壤下渗与储水以及蒸散发等水 循环的主要环节均有布局, 关注的重心主要集中在植 被冠层截留和陆面蒸散发两大关键过程方向; 径流形 成过程与变化方面, 主要考虑陆地植被生态因素影响 下的径流形成过程及其随植被生态系统变化的响应; 陆-气反馈作用的生态水文过程方面，主要集中在陆面 蒸散发驱动的大气降水反馈效应.

综述现有文献，一个共同特点就是每一个热点方 向的研究均涉及多个时空尺度. 在空间尺度, 如图1所 示，生态学重点关注的植物水分利用与调控和碳氮水 耦合循环过程两方面问题的研究, 从植物叶片到生态 系统乃至区域或大陆尺度, 涉及尺度十分广泛; 水文学 关注的水循环过程的研究也从单个植株跨度到流域乃 至大陆尺度. 时间尺度上, 根据针对生态水文问题的特 点, 从秒到数十年, 大部分研究主要集中在从半小时到 年的时间范围内.

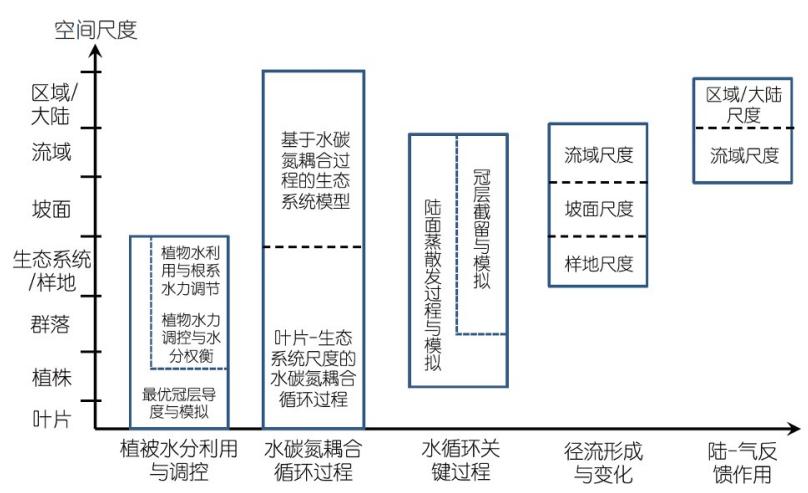

图 1 陆地植被生态水文过程研究关注的热点方向及其空间尺度 格局

Figure 1 The research hot spots of terrestrial vegetation eco-hydrological process and their spatial scale pattern 


\section{2 植物水分利用与调控机制: 从植物个体到 生态系统}

陆地植物对水分的利用与调控始终是生态水文学 研究的核心内容. 除了传统的以水均衡理论和植物蒸 腾过程等为基础的植物水分利用格局与动态研究以外, 近年来有关植物水分利用策略与调控机制方面的研究 更多地关注以下几方面：植物水力特征及其驱动的水 分利用策略、冠层气孔导度及其制约的植物水分利用 与调控过程、土壤水分的生态分离机制以及根系的水 力再分配机制等，并从植物个体向群落和生态系统尺 度拓展.

\section{1 植物水力调控机制与水分利用权衡}

变化环境将导致不同植物(如常绿和落叶植物)在 水分利用策略上呈现不同响应规律，但越来越多的证 据表明，不同乔木的不同水分利用策略更可能与它们 在木质部水分运输的结构和功能(水力结构)的差异密 切相关 ${ }^{[14,15]}$. 植物的水力结构是影响植物生长的水分 供给、叶片气体交换、最大生长高度以及应对气候变 化的适应能力等的主要因素．植物木质部水力特征与 水分传输的安全性和导水效率密切相关 ${ }^{[16]}$. 在生境变 化(如冻融、干旱)、植物的生理生长需求等诸因素作 用下 (如产生气穴化栓塞), 植物木质部在水分传输效 率、水分传输安全性和机械支撑三方面存在一定的 “三角权衡关系”范式，表明植物很难同时在所有功能 上都达到最优化 ${ }^{[17]}$. 然而, 植物所具有的这种权衡能力 存在阈限，如植物木质部导管对干旱诱导的气穴化栓 塞很敏感，严重的木质部栓塞能极大降低植物木质部 的导水能力和安全性，从而制约植物叶片光合生产力, 甚至导致植物死亡 ${ }^{[18-20]}$. 现阶段普遍认为干早诱导树 木死亡的两种生理机制是水力失败和碳饥饿假 说 ${ }^{[21 ~ 23]}$. 但由于不同植物以及不同生长阶段植物水力 结构、水力传导与生理生态过程间极其复杂多变的相 互作用关系, 始终存在较多未知原因, 这些假说还有待 进一步验证 ${ }^{[22,24]}$.

近年来，在探索不同植物面临不同程度水分胁迫 时的生理应对策略中，基于植物叶片水势和蒸腾日变 化规律，提出“等水特性”概念: 在季节尺度上随着土壤 水分胁迫的加剧，等水植物能够维持相对稳定的叶片 水势; 而非等水植物(anisohydric plant)的叶片水势在季 节尺度上逐步下降 ${ }^{[25]}$ ．等水植物自身具有较强的气孔
调节能力, 当所面临的水分胁迫程度逐渐加剧时, 虽然 可以阻止植物木质部栓塞或空穴化，但其更易死于因 碳同化作用受限而引起碳饥饿(carbon starvation); 非等 水植物的叶片气孔对自身水势变化的调节作用相对较 弱，当叶片水势低于某些临界值时，非等水植物更易死 于因出现木质部栓塞化而导致的水力功能故障 ${ }^{[26]}$. 但 现阶段植物等水特性的量化指标尚没有取得普适性进 展，如何基于等水特性理论更加合理地描述植物对变 化环境的响应生理机制仍然面临着较大的挑战 ${ }^{[27]}$.

\section{2 植物水分利用策略与根系水力再分配机制}

不同植物在不同环境和生长阶段的水分利用策略 存在的分异特征及其形成机制，一直是植物学、生态 学和水文学领域关注的热点. 传统土壤水文过程观测 及模型研究, 通常假设降水和土壤水完全混合, 但近期 基于同位素技术的深人分析发现，降水人渗后的土壤 水分可区分为能被植物吸收利用的束缚水和能自由移 动且形成径流的自由水，这一现象被称为生态水文分 离 ${ }^{[28]}$. 生态水文分离现象又分为两类, 当束缚水和自由 水完全不存在交掺混合, 则称他们完全分离; 若存在部 分混合, 则称他们存在连接性 ${ }^{[29]}$. 被植物利用的束缚水 并不参与到平动流而最终形成径流，从而认为土壤束 缚水和土壤自由水是两个独立的水库，称为“二水世 界, ${ }^{[28]}$. 然而, 有越来越多的研究证据表明, 土壤束缚水 和自由水存在部分交换，说明两个水世界假说在许多 场合并不成立 ${ }^{[29]}$. 同时，在一些山区森林生态系统中, 存在旱季完全分离而在湿季为连接性的现象 ${ }^{[28,30]}$; 也 有研究发现土壤含水量较低存在生态水文完全分离, 而当土壤含水量较高时，存在混合现象，表明利用 $\delta \mathrm{D}$ $\delta^{18} \mathrm{O}$ 关系来判别生态水文分离具有很大不确定性 ${ }^{[31]}$. 这一前沿争论, 为生态水文学提出了两个方面亟待解 决的问题：一是需要发展可以准确辨析生态水文分离 的分析方法并完善相关技术手段；二是有必要进行更 多关于植物根系吸水机制的深人研究，以提高对生态水文联系的系统理解.

根系吸水机制解析研究一直备受关注，早在 20 世 纪70 80年代，人们就发现根系与土壤间存在双向水分 交换，在一定的根土环境条件下根系也可以向土壤释 放水分. Richards和Caldwell ${ }^{[32]}$ 在总结前人研究的基础 上将这一现象定义为根系的水力提升(hydraulic lift). 后来研究证实这一根系调水过程可以将任何根系在湿 润区吸收的水分传输到任何方向的干燥土层，不局限 
于在白天和夜间的蒸腾梯度变化的影响，也不完全局 限于下层土壤水分由根系提升向上迁移, 存在表层土 壤水分由根系导人下层干旱土壤的情形. 因此, 也有研 究将其表述为水分再分配(hydraulic redistribution, $\mathrm{HR})^{[33]}$. 近些年来对具有水力提升的植物种类和分布 区域方面的研究又有了更多的发现，越来越多的证据 表明水力提升是植物所具有的一种普遍的土壤水吸收 利用模式, 此现象的发生有其内在机理, 并受一定条件 的约束 ${ }^{[34]}$. 水力提升作用能够改善植物根系及相邻植 物根系土壤水分环境条件, 促进植物水分利用、养分 吸收, 有助于缓解干旱区植物水分胁迫, 对提高植物群 落的稳定性具有重要作用.

自Ryel等人 ${ }^{[35]}$ 建立首个定量描述HR的数值模型以 来，国际上陆续发展了大量从不同角度定量模拟HR过 程的模型. 大多数模型使用Richards方程描述水在非饱 和土壤中的运动，并用“源/汇”概念来描述植物根系水 的吸收或释放. 依据模型结构上的差异, 可将这些模型 划分为4种类型: (1) 土层连接模型 ${ }^{[35]}$; (2) 大根模型 ${ }^{[36]}$; （3）土壤大尺度和根系小尺度融合模型 ${ }^{[37]}$; (4) 动态根 剖面模型 ${ }^{[38]}$. 这些模型在定量分析HR水量及其生态水 文效应方面取得了进展，但仍然面临诸多挑战，如将 HR 模型模拟结果纳人大尺度过程模型(如流域水文模 型、陆面过程模式等), 并提高这些过程模型对一些变 量(如植被蒸腾)的模拟精度; 植被夜间蒸腾和植被地上 部分较高的容水能力对干燥土壤水分的争夺、植被季 节性落叶产生的冠层叶面积指数(leaf area index, LAI) 变化对HR的影响等因素在HR模拟中的定量描述等 ${ }^{[34]}$.

\section{3 最优冠层导度与模拟}

气孔导度决定了陆地生态系统植物的碳水循环过 程, 因此准确定量及模拟气孔导度一直是寻求精确模 拟和预测生态系统水循环和生产力变化的关键. $\mathrm{CO}_{2}$ 同 化量决定了植物生长量, 而蒸腾耗水和气孔的开合模 式则会影响碳同化速率，因此，在漫长的进化过程中, 植物已演化出适应水分亏缺的结构和机制, 以达到对 水分利用的最优化. Cowan和Farquhar ${ }^{[39]}$ 提出了最优气 孔调控理论, 认为气孔的最优化行为就是在某一时间 段内，固定最多碳的同时消耗最少的水. 也就是说，对 一定的碳累积, 最小化蒸腾耗水. 此后, Katul等人 ${ }^{[40]}$ 基 于3个假设(气孔在优化状态下，光合作用受Rubisco活 性限制，并忽略边界层阻力和呼吸作用), 结合经典的 气孔导度模型(BWB模型或BBL模型), 提出了最优气
孔导度的显式函数非线性优化模型和线性优化模型. 但Katul模型也存在一些明显缺陷: 一方面, 该模型需结 合其他气孔导度模型才能计算碳同化的边际水分消耗, 仍然无法由环境因子直接求得最优气孔导度; 另一方 面, 无论是非线性模型还是线性模型, 成立的假设条件 太多，且模型中未引人指示光强和水分状况的环境参 数. Medlyn等人 ${ }^{[41]}$ 认为气孔在优化状态下光合作用是 受RuBP再生限制，否定了Katul模型中的假设(气孔在 优化状态下, 光合作用受Rubisco活性限制), 建立了形 式上类似BBL模型的最优气孔导度模型. 与经典的半 经验模型相比, Medlyn模型对气孔导度的模拟更加准 确, 更重要的是模型中的参数与边际水分利用效率具 有一定的比例关系, 赋予了该参数生物学意义, 使模型 可以用来描述植物的水分利用策略. 无论是Katul模型 还是Medlyn模型，水分利用最优时的气孔调控都与碳 同化的边际水分消耗相关. 目前的研究认为在更长的 时间尺度上碳同化的边际水分消耗并不是恒定不变 的 ${ }^{[42]}$, 但现有的研究仍不能确定不同环境条件下碳同 化的边际水分消耗值. 因此, 未来需要系统明确碳同化 的边际水分消耗与环境因子的定量关系及生物学意义.

最优气孔调控理论的提出为模拟不同植被在不同 环境下的气孔导度提供了新思路, 有助于将基于最优 气孔调控理论的机理模型与冠层或区域尺度相关模型 耦合, 应用到更大空间尺度的碳水循环模拟研究 ${ }^{[43]}$. 如 将最优气孔导度模型耦合到陆面过程模式中, 就可以 模拟不同区域的蒸腾和能量通量. 然而, 由于碳同化的 边际水分消耗等参数在长时间尺度和大空间尺度上的 可变性, 且我们对其变化规律的理解还十分有限, 所以 即便耦合了含有生物学意义的机理模型，更大时空尺 度碳水通量的模拟仍存在较大不确定性 ${ }^{[42,44]}$. 需要进 一步深化对植被本身差异(如生长状况、发育阶段和 植物形状等)以及不同环境条件(如土壤水分状况、 $\mathrm{CO}_{2}$ 浓度和光照等)下的气孔调控行为的理解，从机理 上建立水分利用最优时气孔导度与环境因子和生理因 子的定量表达方法; 同时, 需要加强气孔导度机理模型 和地球系统模型的多模型耦合，推动基于冠层尺度的 机理模型向大尺度水碳循环精准模拟发展.

从自然生态演替角度，经过自然选择后的稳定或 顶级生态系统的生态水文过程也必然遵守上述最优性 原则. 一般地, 制约光合作用强度的主要外部因素有气 候因子(温度、水分、光照、二氧化碳)以及土壤矿物 质和养分供给水平等 ${ }^{[45]}$. 在充分供水条件下, 适宜于当 
地环境气候温度的物种应该满足最优温度状态条件, 且自然光强即为最优适宜光强. 当出现水分胁迫时可 使光合速率下降, 就存在水分临界光强. 在自然光强超 过水分临界光强时，植被将通过关闭气孔或减小冠层 覆盖度以维持正常的光合作用, 就出现植被群落结构 的改变 ${ }^{[4]}$. 由此, 将植被冠层的状态参数(覆盖度、冠层 阻抗、冠层导度)与土壤水分状态、气候因素决定的 生长温度等连接在一起，可实现从机理上阐述冠层阻 抗的内部优化与冠层生产力权衡的外部优化条件 ${ }^{[4,45]}$ 这一最优性原则的拓展，为我们从机理上判识特定气 候与水分条件下适宜植被格局提供了理论基础，广泛 应用于特定区域(如黄土高原)水分均衡植被覆盖模式 的确定 ${ }^{[46]}$, 解释北方森林带局部区域土壤干燥化演变 的植被因素及其贡献等. 现阶段这个领域面临的最大 挑战在于: (1) 准确判识不同植被类型的适宜性生长温 度与水分临界阈值及其时空分异规律; (2) 探索两个相 反且统一的人为调控策略: 维持现有生态系统稳定的 水分调控途径与模式、促进次生植被演化进程以实现 稳定的顶级植被群落格局.

\section{3 碳氮水耦合循环过程与模拟: 从叶片到 区域}

水既是植物细胞的重要组成成分, 又是植物代谢 过程的原料和各种生理生化反应与物质运输的介质. 植物通过光合作用进行碳交换和蒸腾(水交换), 而光合 作用又受植物叶片的气孔行为所控制, 氮代谢通过控 制气孔行为和碳同化合成过程决定光合作用能力，从 而形成了生态系统碳-氮-水耦合循环的内在生理生态 学基础, 也成为辨析植物应对环境胁迫策略的主要途 径. 以植物叶片的碳-水生化反应理论为基础, 发展了 叶片及冠层尺度基于生理生化机理的气孔导度理论与 数值模型 ${ }^{[47]}$, 并实现了多过程耦合, 如其中应用较为广 泛的Ball-Berry模型就与光合作用模型、水汽和 $\mathrm{CO}_{2}$ 的 传输模型以及热量平衡模型相结合. 氮代谢通过控制 气孔行为和碳同化合成过程决定光合作用能力, 形成 了生态系统碳-氮-水耦合循环的内在生理生态学基 础 $^{[48,49]}$. 植物体内碳-水间的生化反应、叶片和冠层尺 度气孔对光合-蒸腾的共同控制和优化调控作用，共同 构成了碳-水耦合的基本作用机制. 近年来，大量研究 逐渐认识到气孔作用似乎具有某种优化调控机制，可 使得植物能在适当的水分“损失”水平上获得最大量的 $\mathrm{CO}_{2}$ 同化, 但其作用的机理尚不完全清楚 ${ }^{[49,50]}$. 土壤水
分如何作用于氮循环也是水-氮耦合关系组成部分，如 土壤干旱会抑制硝化作用, 导致氮素在土壤中积累; 在 土壤潮湿条件下, 氮矿化一般会增加 ${ }^{[48,51]}$.

从理论上，根据叶片氮含量与最大光合能力的相 互关系来看，增加叶片氮含量应该会使单位叶质量的 碳收益成比例增加, 但是大量研究结果表明, 这种正效 应存在一定的阈值 ${ }^{[52]}$. 伴随环境变化, 认为植物对叶绿 素、核酮糖二磷酸羧化酶等光合作用成分的氮分配可 根据环境条件进行优化，但作用机理以及是否存在优 化功能的有效阈限和边界条件等尚待进一步探索 ${ }^{[3,54]}$. 土壤水分的有效性对光合作用和氮供应能力均具有重 要影响, 降水增加之所以倾向于增加净生态系统碳交 换量(net ecosystem carbon exchange, NEE), 可能是因 为水分利用率增加了光合作用，而没有增加植物的呼 吸损失. 一般而言, 温度倾向于强化生态系统中氮的微 生物和非微生物转化过程(例如矿化、反硝化、分解 和硝化作用等), 而水分有效性可调节生物动力学温度 响应程度，直到这个过程达到温度和水分共同作用的 最佳状态 ${ }^{[5]}$. 但我们始终不清楚降水和蒸发如何共同 影响土壤微生物过程, 从而改变生态系统的氮供应; 同 时, 还需要深化探究相对水的可用性如何放大或减弱 氮转化对温度的反应 ${ }^{[56]}$.

早在 20 世纪 90 年代，人们就着手探索将植被冠层 的温湿度耦合过程与土壤水热耦合传输过程相结合, 通过地上植被-土壤界面的水热传输机理，发展植被冠 层水热扩散模型与土壤水热迁移模型耦合的SPAC系 统整体水热传输模型 ${ }^{[57]}$. 进人 21 世纪以来, 很多学者进 一步探索SPAC连续体中的其他物质传输过程, 特别是 养分和盐分与水热的耦合传输过程. 比如将描述植物土壤碳氮传输的DAISY模型与SPAC水热耦合传输模 型相结合，发展了SPAC系统水热碳氮多元耦合传输模 型 ${ }^{[58]}$, 在农业生产系统水氮管理和有机无机配施方面 取得了应用进展 ${ }^{[59]}$. 这方面突出的模式进展大部分都 在新发展起来的基于生物物理机制的区域生态模型有 所考虑，也被纳人到一些新近发展起来的陆面过程模 式中.

现阶段几乎所有基于过程的生态系统模型(如 GDAY、DAYCENT、TECO、TEM)、陆面过程模式 (CABLE、CLM、EALCO、ISAM、OCN等)以及全球 动态植被模型(LPJ-GUESS, SDGVM等)等, 均包含较为 完善的C-N耦合循环过程模块. 包括植物碳获取、氮固 定与吸收、氮周转、生态系统呼吸以及植物不同器官 
的 $\mathrm{C}: \mathrm{N}$, 也包括土壤有机质的生物计量平衡、有机质分 解、氮转化以及土壤 $\mathrm{N}$ 流失等, 能够识别不同生态系统 在不同变化环境下的C-N循环过程响应及其对生态系 统碳/氮库的影响 ${ }^{[60-62]}$. 然而, 这些模型中, 对水循环过 程的考虑则存在较大差异. DAYCENT、TEM、LPJ等 模型简单考虑了土壤水分动态的影响, 只有少数模型 如OCN、EALCO、CLM等对水循环过程的考虑相对 全面，包含了土壤水分动态、蒸散发以及径流等水循 环过程的影响. 如何实现对生态系统碳氮循环以及生 产力演化中水循环过程的准确识别, 始终是生态系统 模型亟待解决的瓶颈 ${ }^{[61,62]}$. 实际上, 基于过程的生态系 统碳-氮-水耦合模型的发展需要将碳氮耦合过程模型 与基于生态水文物理机制的水文模型进行全耦合.

\section{4 水循环关键过程的陆地植被作用: 从植物 个体到区域}

陆地植被生态系统对水文循环影响的主要表现形 式是生态系统对降水和土壤水的再分配以及蒸散发, 并通过对降水截留、蒸腾、下渗以及储存等过程的影 响，对流域的径流形成和流域水文情势等具有重要作 用. 早在 20 世纪 90 年代初期国际IGBP研究计划提出的 核心内容“水文循环的生物圈方面(BAHC)”，其核心任 务就是要明晰生物圈对水循环的控制作用及其对气候 和环境的重要性, 提供综合而简化的生态水文模型, 并 把它耦合到流域水文或陆面过程模式中 ${ }^{[63]}$. 此后的十 多年, 全球范围内开展大量有关水循环的植被作用过 程、机理与模拟等方面的研究, 促使人们认识到对水 循环生物作用机理的深人理解是水文循环过程准确认 知的关键，一切基于物理机制的水文模型面临的最大 挑战也在于对水循环过程中的植被作用如何定量刻 画 ${ }^{[64]}$. 其中植被冠层截留和陆地实际蒸散发是水文循 环生物作用研究的两个重点环节.

\section{1 植被冠层截留}

林冠截留是水文循环的重要组分, 同时也是所有 水文模型中的关键水文变量. 过去几十年, 针对不同森 林类型的林冠截留已开展了大量的观测研究工作, 但 是这些基于林分和典型生态系统尺度的观测结果无法 直接尺度上推到流域、区域尺度或全球尺度. 因此, 模 型模拟就一直是植被冠层截留研究的主要方向.

现有的植被冠层截留模型多种多样, 包括简单的 经验模型、概率统计模型、基于物理机制的机理模型
等. Muzylo等人 ${ }^{[65]}$ 对比分析了目前国际上最常用的 15 种基于物理机制的林冠截留模型，并基于这些模型对 降雨再分配所采用的分析方法将其分为两大类：一是 采用降雨的概率分布来分析截留的动态变化，这类模 型以Calder模型为主要代表; 二是采用连续水均衡方程 处理降雨量的再分配过程, 这类模型占据绝大多数, 可 进一步分为Rutter模型类和Gash模型类两类 ${ }^{[10,65,66]}$. 由 于Calder模型所需参数较多(双层模型需要至少 16 个参 数), 计算相对复杂, 应用具有一定局限性. 如果从模型 可以同步输出截留量 $(I)$ 、穿透降雨量 $\left(T_{f}\right)$ 以及树干茎流 $\left(S_{f}\right)$ 角度, 现阶段广泛使用的主要机理模型可以归纳为 Rutter和Gash模型两大类8种模型 ${ }^{[66,67]}$. 由于 Gash截留 模型是由Rutter模型简化而来，相对Rutter模型的参数 系统要简单, 因此应用最多 ${ }^{[10,67]}$. Gash模型将降雨划分 为一系列离散的降雨事件，假设相邻降雨事件的时间 间隔足使林冠完全干燥，每个降雨事件又被划分为林 冠湿润期、冠层饱和期和冠层干燥期 3 个阶段. 大部分 的研究显示, 模型中最重要的敏感性参数是冠层和茎 干的平均蒸发率和林冠储水量. 因此, 针对冠层降雨干燥期的假定，Gash模型的应用就有了一些针对性的 改进, 以便用于降水充沛和极端湿润环境的植被截留 模拟, 如发展独立的冠层蒸发和储水量模型 ${ }^{[68]}$, 嵌套能 水平衡模块 ${ }^{[69]}$ 以及发展雨滴模型 ${ }^{[70]}$ 等. Rutter和Gash类 模型在年均截留量模拟精度较高，误差一般小于 $11 \%$, 甚至不足 $5 \%{ }^{[10,67]}$. 基于遥感数据反演和大尺度气候数 据的可获得性，植被冠层截留定量模拟在大尺度扩展 方面也取得了较大进展，如Miralles等人 ${ }^{[71]}$ 利用气候预 测中心多源数据融合的 $(\mathrm{CMORPH})$ 全球降水数据产品, 结合MODIS植被覆盖数据, 驱动改进的Gash模型, 获得 了全球主要森林植被类型的林冠降水截留量数据.

总结近年来林冠截留数值模拟(主要是应用Gash 和Rutter模型)结果, 目前存在的亟待解决的主要问题 有: (1) 大部分林冠截留评估结果在月均和年均尺度上 的累积截留量有较为满意的结果(误差一般小于 $15 \%$ ), 但在评估次降雨事件的截留时, 模型的模拟能力和准 确性显著下降(确定系数 $R^{2}$ 一般小于 0.4 ); 同时, 机理模 型不能适用于过低(如低于 $1.2 \mathrm{~mm}$ ) 和过高降雨强度 $(大$ 于7.0 mm)的情形 ${ }^{[10,70]}$. (2) 大部分模型适用于林分甚至 单株树木尺度，在具有复杂植被类型的坡面、流域或 区域尺度上，采用平均的冠层饱和持水量、相对固定 的冠层郁闭度等所带来的较大误差. 较大空间尺度上, 模型的模拟精度依赖于参数的尺度上推的可靠性，如 
冠层饱和持水量随叶面积指数LAI的时空变化、树冠 郁闭度(或覆盖度)的空间和季节变化等 ${ }^{[71]}$. (3) 模型普 遍低估了实际植被冠层的降水截流量. 上述这些问题 产生的主要因素重点缘于三方面: 参数赋值误差、观 测数值不准确以及对植被冠层截留机制的理解不全 面 ${ }^{[10,65]}$. 其中, 输人参数的不确定性导致的误差占据主 导地位, 如对冠层蒸发 $\mathrm{Er}$ 参数的评估, 无论使用物理机 理方法(如P-M模型等)或经验的水均衡方法，通常会导 致较大的系统性偏差 ${ }^{[69-71]}$, 因此, 迫切需要进一步深人 了解截留水量蒸发的能量及其影响因素等. 另外, 需要 着眼于获得可靠的冠层空间特性监测值, 将林冠蓄水 量变量分解为易于测量的物理组分以获取高质量的林 冠蓄水量数据, 对提升截留模拟精度至关重要 ${ }^{[69,71]}$. 模型普遍没有考虑植被生长过程引起的冠层结构参数 的动态变化对冠层截留的模拟.

\section{2 蒸散发过程}

由于植被蒸腾占陆地蒸散发的 $80 \%$ $90 \%$, 是陆-气 水分交换的主要途径 ${ }^{[72]}$, 因此, 陆地植被生态系统参与 下的实际蒸散发机理与准确模拟研究一直是陆地水循 环研究的焦点. 针对陆面实际蒸散发评估, 尽管有大量 分析方法，但应用最广泛的方法可以归纳为基于能水 平衡的以气候要素驱动的模拟方法和基于植物水分传 输机制的以气孔导度为驱动的水碳耦合分析方法两 大类.

在碳水耦合分析角度，现阶段基于叶片尺度气孔 导度模型，是生态系统乃至区域尺度基于遥感反演蒸 散发的理论基础. 从叶片尺度发展到植物冠层尺度的 气孔导度模型，其理论模型的发展经历了从单个大叶 模型发展到双叶模型，以及后来进一步发展到多层-双 叶模型 ${ }^{[73,74]}$. 多层-双叶模型的发展, 不仅关注植物冠 层和环境的垂直结构变化的互馈作用，而且也考虑将 受光的叶片和被遮阴的叶片进行区别分析，可以较为 客观揭示冠层内物质输送与能量交换中气孔传导特性 和叶层能量平衡特点, 减少冠层内的各要素廓线模拟 值的误差, 提高整个冠层显热、潜热和 $\mathrm{CO}_{2}$ 通量的计算 精度 ${ }^{[75,76]}$. 基于叶片气孔导度模型发展了多种陆地生 态模型(TBMs), 广泛用于定量模拟植被冠层和生态系 统尺度的碳水交换通量. 但这些模型验证和模型间比 较表明, TBMs对叶片光合能力的参数化特别敏感，由 于叶片光合参数只能在叶片水平上直接测量, 因而这 些参数在较大时空尺度上的有效性限制阻碍了 $\mathrm{TBMs}$
(也包括气候模式和陆面过程模式)对总初级生产力 (gross primary productivity, GPP)和蒸散发(evapotranspiration, ET)估算精度的提升 ${ }^{[72,77]}$. 因此, 现阶段迫切 需要解决的问题是: 改进气孔导度模型的参数化, 包括 从物种特异性到生物群落特异性的参数, 并确定气孔 导度模型参数响应持续环境变化的可塑性和适应性, 以便在多种尺度上应用，特别是提高对全球陆地植被 生产力、水文循环过程等模拟的精度 ${ }^{[78]}$.

近年来, 研究发现叶片叶绿素含量 $\left(C h l_{\text {leaf }}\right)$ 与表征 叶片光合能力的最大羧化能力 $\left(V^{25}\right.$ max $)$ 和最大电子输运 能力 $\left(J^{25}{ }_{\text {max }}\right)$ 间存在密切关系 ${ }^{[79,80]}$, 由此逐渐发展起来了 基于 $C h l_{\text {leaf }}-V_{\text {max }}^{25}$ 关系嵌套的多层-双叶模型，显著提升 了在较大空间尺度上基于气孔导度机理模型对ET的模 拟精度 ${ }^{[80,81]}$, 为解决基于机理的大尺度蒸散发精确模 拟提供了有效探索途径. 然而, 不同的植物功能类型 $C h l_{\text {leaf }}$ 和 $V^{25}$ max 的季节变化差异显著, 因此, 大尺度植物 功能类型分布格局的准确度决定了 $C h l_{\text {leaf }}-V_{\text {max }}^{25}$ 关系的 准确性. 但是现有的大尺度植物功能类型分布图中往 往缺失某些物种(特别是 $\mathrm{C}_{4}$ 植物)的分布情况, 这就极大 地限制了这一关系模型在更大尺度上的应用 ${ }^{[79,80]}$. 另 外，包含常绿植物的群落往往包含大量不同年龄的叶 片，而不同年龄叶片的 $C h l_{\text {leaf }} V^{25}$ max 关系表现出不同的 季节变化趋势, 比如幼龄针叶和老龄针叶的 $C h l_{\text {leaf }}$ 含量 呈相反的变化趋势. 而在获得 $C h l_{\text {leaf }}$ 或建立 $C h l_{\text {leaf }}-V^{25}{ }_{\text {max }}$ 关系时, 并未考虑叶龄这一因素的影响 ${ }^{[22,83]}$. 未来需要 利用站点数据建立 $C h l_{\text {leaf }}$ 或 $C h l_{\text {leaf }}-V_{\text {max }}^{25}$ 与叶龄的关系, 并准确量化老叶与新叶的比例，以提高区域蒸散发模 拟的精度.

从能水平衡分析角度，基于互补理论的蒸散发模 型的发展和应用成为近年来陆地蒸散发模拟研究的主 流. 在过去的几十年里, 已有多种基于互补相关理论的 线性模型先后提出，其中比较常见的有平流-干旱模型

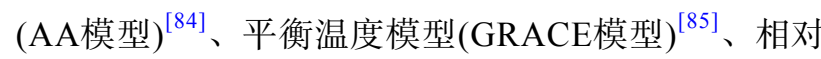
蒸散发模型(GG模型) ${ }^{[86]}$ 等. 此后, 大量不同下垫面条件 下的研究(如干旱和湿润环境下)发现, 非线性互补关系 更具有广泛性，由此修正了原有线性关系模型，并提出 了广义非线性互补原理模型 ${ }^{[87,88]}$. 近年来, 围绕这一广 义互补原理模型, 相继提出了一些修订模型, 并进一步 发展了不需要率定的非线性互补关系模型 ${ }^{[89-91]}$. 互补 关系理论考虑了蒸散发对大气变量的反馈作用，明确 了实际蒸散发和潜在蒸散发的相互关系，直接在区域 尺度建立方程, 适用于区域尺度蒸散发的模拟. 互补关 
系理论将复杂的土壤-植被-大气系统的水文过程归结 到气温、湿度和辐射等几个气象要素的变化规律上, 不需要空气动力学导度、土壤理化性质等难以获取的 资料, 仅需常规气象观测资料就可估算实际蒸散发量. 因此，广泛应用于不同时空尺度、不同下垫面条件的 蒸散发模拟研究, 成为实际蒸散发定量模拟分析领域 最具活力的方向之一 ${ }^{[92,93]}$. 但是, 对非线性广义互补关 系中各参数的变化规律及影响因素仍然不清晰, 仍需 进一步揭示实际蒸散发与辐射项、空气动力项在不同 环境和下垫面条件下的相互作用机制.

\section{5 陆地植被生态因素作用下的径流形成与变 化: 从坡面到区域}

径流形成与变化中的生态因素与作用机制及其定 量模拟, 一直是水文学最为重要的前沿领域, 主要关注 典型样地、坡面和流域等 3 个尺度的径流形成过程与 动态变化. 近年来, 利用遥感技术和大数据分析手段, 该领域研究逐渐向大陆和全球尺度拓展. 在植被生态 因素方面, 重点关注植被覆盖变化、植被结构与组成 变化以及土地利用变化等方面. 系统归纳最近10 15年 在不同尺度上围绕径流形成的生态作用问题研究进展, 如表1所示, 大致可以总结以下几方面的进展及其存在 的主要挑战.

\section{1 样地尺度}

样地尺度包括野外基于多种尺度径流观测试验场 地和实验室模拟试验样地的观测试验研究, 是探索地 表产流过程与机制最主要的观测试验尺度. 在这个尺 度上大量观测研究的结果基本一致：对同一植被类型， 高植被覆盖度形成较小产水量; 森林植被对产流的抑 制作用最为显著. 但越来越多的研究结果认为人工森 林植被的减流效应与土壤质地和根系等因素的间接作 用关系密切, 存在明显的时间尺度效应，一般植树时间 越长，对地表产流和地下径流组分的影响就越大 ${ }^{[94 ~ 96] ; ~}$ 植被结构越复杂, 地表径流减少幅度就越大 ${ }^{[97,98]}$, 因而 具有复杂结构的自然森林植被比单一人工植被减少地 表产流能力更大 ${ }^{[99,100]}$. 现阶段面临的最大挑战性问题 是: (1) 不同植被类型与结构对土壤水分分布与运动过 程的影响程度与作用机制等, 尚未取得普适性的理论 认识, 也缺乏基于机理的定量刻画方法; (2) 植被类型 或结构改变对土壤水力性质的重塑, 存在时间尺度上 动态演变和不同植被与土壤类型的较大变异性, 对产
流过程具有何种影响, 并如何从物理和生态学机理角 度与坡面和流域尺度的径流形成相衔接.

\section{2 坡面尺度}

在坡面尺度上的观测试验研究, 可以有效揭示暴 雨地表径流与地下径流的各自形成过程及其对总体径 流形成的影响，区分基流来源及其对变化环境的响应 等. 因此, 坡面水文过程是认知不同下垫面环境下径流 形成、组成及其动态变化机制, 以及发展基于物理机 制的水文过程模型等的最重要和最普遍采用的研究尺 度. 在这个尺度上, 发现地表径流与植被覆盖度成反比 的现象存在降雨强度阈值, 径流过程受到前期土壤含 水量、降雨历时、降雨强度以及地被层性质等诸多因 素的共同影响 ${ }^{[101 ~ 103]}$; 大量观测结果表明自然复杂植被 坡面地表产流减少幅度高于单一植被类型或短期人工 森林, 但可显著提高基流量, 增大枯水流量; 相同植被 类型(森林或草地), 土壤有机质层和根系层发育程度对 径流形成过程具有较大影响, 这与土壤储水能力和土 壤有机质的疏水性和饱和渗透性能有关 ${ }^{[101,104]}$. 短期具 有较高密度的人工林地对基流的影响高于其他土地利 用类型, 而具有复杂植被结构的自然林地对消减洪峰 流量的作用最大 ${ }^{[95,100,103,105]}$. 目前面临的最主要挑战: (1) 系统识别坡面径流与暴雨洪水流量形成的降水、 前期土壤含水量以及土壤水分國值, 并明晰这些阈值 随植被类型、结构和土地利用格局的变化规律; 据此, 深化对不同生态条件下坡面产流机制的理解. (2) 探索 径流形成过程、临界条件以及驱动因素与作用机制等 的参数化表达, 发展生态与水文全过程耦合的坡面水 文模型. (3) 流域尺度. 关于土地利用与覆盖变化对径 流影响的争论已有上百年历史, 至今仍然处于激烈辩 论而缺乏共识性认识 ${ }^{[106]}$. 在过去近 100 年里, 全世界大 约有 250 个公认流域配对试验, 结果表明, 虽然有大量 试验流域存在植被变化与水资源之间呈现显著负相关 性, 但也存在一些流域植被覆盖变化或土地利用变化 对产水量影响甚微, 甚至是正效应 ${ }^{[106,107]}$. 统计分析认 为, 具有正效应和无效应的流域, 要么地形复杂、面积 大, 要么位于湿润气候区, 即取决于流域持水能力和气 候湿润程度 ${ }^{[107]}$. 对人工造林和农作物为主导植被的流 域, 群落组成结构或空间分布格局变化对径流过程有 较大影响. 如Elliott等人 ${ }^{[108]}$ 通过对具有 80 多年长时间 比较试验流域观测结果分析发现, 森林群落由原来的 环形木质树种为优势更替为散射型木质树种为优势, 


\section{表 1 基于观测试验的植被生态因素变化对径流形成的影响及其在不同尺度上的体现}

Table 1 The impacts of shifts in vegetation ecological factors on runoff processes based on experimental observation and their embodiments on different scales

\begin{tabular}{|c|c|c|c|}
\hline & 样地 & 坡面 & 流域 \\
\hline $\begin{array}{l}\text { 植被覆 } \\
\text { 盖变化 }\end{array}$ & $\begin{array}{l}\text { 地表产水量与植被覆盖度成反比; 植 } \\
\text { 被覆盖影响大于土地耕作方式 }\end{array}$ & $\begin{array}{l}\text { 地表径流与植被覆盖度成反比, 存在降雨强度國 } \\
\text { 值; 植被覆盖度对地表径流的影响取决于降雨历 } \\
\text { 时、降雨强度和地被层分布特征 }\end{array}$ & $\begin{array}{l}\text { 人工植被覆盖变化对径流的正负影响及程 } \\
\text { 度取决于流域持水能力和湿润条件; 自然植 } \\
\text { 被覆盖变化几乎无影响 }\end{array}$ \\
\hline $\begin{array}{l}\text { 植被结 } \\
\text { 构变化 }\end{array}$ & $\begin{array}{l}\text { 结构变化比覆盖度变化对产流影响 } \\
\text { 更大; 复杂植被结构(乔木+灌木+草 } \\
\text { 本)比单一植被结构径流减少更大 }\end{array}$ & $\begin{array}{l}\text { 自然森林植被降低径流、增加枯水流量占比的 } \\
\text { 幅度高于工森林和其他单一植被结构; 纵向植 } \\
\text { 被结构对径流的影响取决于水力连通性 }\end{array}$ & $\begin{array}{l}\text { 植被结构与组成显著影响径流量及其季节 } \\
\text { 分布; 植被景观破碎化程度显著影响地表径 } \\
\text { 流, 植被结构的影响取决于水力连通性 }\end{array}$ \\
\hline $\begin{array}{l}\text { 土地利 } \\
\text { 用变化 }\end{array}$ & $\begin{array}{l}\text { 相比农田, 草地减少径流<灌丛<森 } \\
\text { 林, 森林+草地减少径流>森林>草地; } \\
\text { 造林时间越长, 森林植被对产流的间 } \\
\text { 接影响越大 }\end{array}$ & $\begin{array}{l}\text { 自然森林消洪能力高于其他土地利用, 人工林减 } \\
\text { 少枯水流量最大; 天然草地基流大于农田和重度 } \\
\text { 放牧草地; 人工林地对径流及其组分的影响与地 } \\
\text { 被层性质、土壤质地以及根系等因素的发育程 } \\
\text { 度有关 }\end{array}$ & $\begin{array}{l}\text { 径流量和径流系数沿森林-草地-农田转变存 } \\
\text { 在显著增大、变化不显著或减小等不同现 } \\
\text { 象, 与流域持水能力大小和干旱程度有关; } \\
\text { 土地利用变化对径流影响程度与时空尺度 } \\
\text { 有关; 降雨强度和前期土壤含水量阈值随土 } \\
\text { 地利用变化而改变; 流域土地利用变化对径 } \\
\text { 流影响与实际蒸散发有关, 取决于植被“蒸 } \\
\text { 发效应”与“渗透效应”间的权衡 }\end{array}$ \\
\hline 文献 & [94 100] & {$[95,100 \sim 105]$} & {$[11,105 \sim 112]$} \\
\hline
\end{tabular}

导致径流量显著减少. 在农田主导的流域, 农作物斑块 的破碎化程度、空间连接度等是影响径流形成与季节 分配格局的主要因素 ${ }^{[11]}$. 土地利用变化的径流影响一 直是流域尺度关注的焦点, 大量基于观测试验和数学 模型模拟的结果都支持一些共性认识，如径流量和径 流系数沿森林-草地-农田转变而显著增大、径流形成 的降雨强度和前期土壤含水量阈值随土地利用变化而 改变; 流域土地利用变化对径流影响与实际蒸散发有

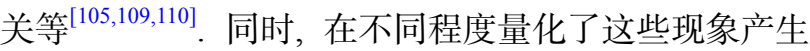
的因果关系的基础上，不断发展流域分布式水文模型， 形成了针对不同土地利用和生态条件下的水文过程参 数化方案. 但近年来, 越来越多的观测研究揭示出流域 土地利用变化对径流影响程度和作用方式等，可能与 时空尺度密切有关，如大于 $10000 \mathrm{~km}^{2}$ 的流域、土地利 用变化超过 50 年后，径流变化可能趋于不明显 ${ }^{[111]}$ 。也 有观点认为森林植被转化为农田或草地，对流域年径 流总量和季节性径流总量的影响部分取决于相关的蒸 散发(原效应)和渗透(海绵效应)变化之间的权衡. 森林 和水的关系一直存在争论，大多数证据表明植被的增 加会导致产水量减少，但是仍然有少数证据表明植被 变化对产水量的影响很小, 甚至导致产水量增加, 出现 正效应和无效应结果的地区大多为湿润地区、复杂地 形或大流域 ${ }^{[111]}$. 周国逸等人 ${ }^{[112]}$ 通过“自上而下”理论框 架阐述了植被与水资源的关系，解释了并非所有的人 工植被恢复都会减少水资源原因。森林条件下的高渗 透能力有利于雨季降水对深层土壤和地下水的补充和
储备, 从而保障森林覆盖土壤有足够的水分储存, 可以 将湿润季节的渗透降雨“携带”到随后的旱季，维持旱 季森林植被生长的水分需求; 同时, 增加的地下水和深 层土壤水分补给有助于减缓旱季地下水退水过程，从 而在整个旱季维持基流保持相对稳定．这些水文效应 是农田和草地植被所不具备的, 因此, 需要对森林植被 的“泵效应”和“海绵效应”的权衡与综合分析, 来确定其 实质的流域或区域水文影响 ${ }^{[13]}$.

实际上，流域尺度土地利用变化对径流过程的影 响是水文学长期争论的焦点问题之一，在气候变化背 景下，厘清流域土地利用与覆盖变化如何以及在多大 程度上影响径流过程，并定量甄别气候变化和人类活 动的影响, 仍然是持续研究的热点 ${ }^{[106,109,110,114]}$. 其中, 关键的制约性问题有两方面：一是土地利用变化对流 域径流过程的影响在不同时空尺度上的表达与演化趋 势; 二是系统集成流域土地利用变化的植被因素、根 系层范围土壤(或岩土)性质演变、生态格局的时空动 态与水力连通性、生态因素作用下的降水-土壤水-地 下水水力联系等因素对水文过程的影响，发展能够更 加全面描述流域生态水文过程的定量模拟方法.

\section{6 陆地植被覆盖变化对大气降水过程的反馈 影响: 从流域到大陆}

陆-气反馈作用包括陆地系统对气候的改变及气候 对陆地系统的改变两方面. 从陆地系统改变影响气候 方面来讲，长期以来的大量研究结果支持植被的蒸散 
发会增加大气的湿度、加速大气中水汽迁移，进而增 加当地及顺风方向地区的降水量并最终增加径流量, 且这种蒸散发-大气水汽-降水量的联结机制似乎是陆 地内部水循环的主要途径, 由此可以认为植被通过调 节地表和大气之间的水分、能量和气体通量来影响降 水模式. 森林的蒸腾作用(增加大气的水汽)及降温作用 会增加大气的相对湿度, Spracklen等人 ${ }^{[115]}$ 采用热带降 水和植被的卫星遥感数据, 结合模拟的大气输送模式, 发现经过热带高密度森林植被区的大气降雨至少是经 过稀疏植被区大气降水的两倍. 因此, Ellison等人 ${ }^{[116]}$ 认 为森林覆盖与降水有着不可分割的联系，应从降水来 源的角度(供给或supply side)来认识森林植被蒸散发, 而不是把它作为径流量的一种损失 (demand side). 从 某一特定集水区由森林驱动的蒸散作用蒸腾的水汽, 有助于增加相邻区域大气水汽的可得性并实现跨大陆 运输, 提高降水事件的可能性, 增加下风向区域水产量. 这一机制对远离海洋的大陆内部尤为重要, 从海岸穿 过森林的内陆横断面通常比那些没有森林的土地有更 高的降水量 ${ }^{[117]}$. 如研究发现通过亚马孙森林, 沿着连 接大西洋和南美洲西北部和南部的流经森林的风流线, 随与海洋的距离增大, 降水量呈指数级增加 ${ }^{[118]}$. 同样, 在中国北部和东南部，尽管植被绿化和增加的森林面 积所增加的降水量在统计上不显著, 但提供了足够的 土壤水分来抵消增强的ET，从而减弱了ET增加对土壤 湿度的影响 ${ }^{[119]}$. 因此，森林退化或丧失的一个主要后 果可能是破坏大尺度水汽形成与传输机制, 对大陆降 水产生广泛影响, 如果忽略这一影响, 对较大尺度上 (大型流域或大陆区域)分析土地利用与覆盖变化的水 文影响就可能严重失真.

然而这种由蒸散发增加的大气水汽，何时、何 地、用何方式变成降水就有非常高的不确定性，但普 遍认为它们可能与流域大小、地形、风向及风速等因 素有关 ${ }^{[120]}$. 尽管下垫面的改变与气候的反馈影响产流 量, 但世界范围内的对比流域实验一致证明森林砍伐 会增加径流量, 而造林会降低径流量这一结论, 说明这 种反馈还不足以在小流域尺度上改变水量平衡中各主 要项的关系. 多数研究结果均表明在大陆尺度上, 植被 覆盖变化引起的蒸散发增加对区域降水的反馈影响将 会数倍于局地尺度(或流域尺度) ${ }^{[116]}$. 这就是形成大陆 尺度或大型流域(数千 $\mathrm{km}^{2}$ 以上)森林覆盖增加可能增大 径流(或产水量的影响微弱)这一有悖于小流域尺度观 测结果的原因之一. 然而, 一方面, 如何准确解析特定
流域或区域降水量的变化中来源于内陆植被覆盖变化 的水文反馈及其贡献范围等是现阶段面临的难题，其 挑战性还在于这种来源与贡献量随季节以及区域气候 而发生较大变化 ${ }^{[119,121]}$. 另一方面, 气候变化由于改变 物种向北迁移、植被结构组成与生物多样性改变、林 线或树线上移等, 无疑将较大幅度改变陆地系统的蒸 散能力, 迫切需要解决的问题是这种变化将如何并在 多大程度上对陆地降水格局产生影响.

\section{7 结论与展望}

陆地植被生态水文学理论体系的发展, 很好地诠 释了生态水文学是探索从分子到流域尺度生物与水相 互作用关系的完整科学. 总结以上分析结果, 陆地植被 生态水文学领域在不同尺度上以及跨尺度拓展方面取 得的理论和方法进展，可以归纳为图2. 核心是将基于 叶片、冠层尺度的机理认识和模拟方法应用于生态系 统和坡面尺度的水文过程的辨析和模拟，并进一步实 现了向流域乃至区域尺度推绎.

（1）基于植物细胞水分吸收、细胞间水分运转、 光合作用驱动的水分散失等构成的植物水分代谢机理, 形成了以能水耦合运动物理过程和植物生理生化过程 相结合、从植物叶片到植物个体再到生态系统尺度的 生态-水文关系理论和方法体系，发展起来了以植物水 力学、光合导度最优化原理等为基础的水分利用与再 分配、冠层水分最优调控、碳氮水耦合循环等一系列 陆地植被生态水文过程的基础理论范式. 包括基于过 程机理的定量描述方法和数值模型, 实现了从植物叶 片气孔作用到流域能水循环过程的跨尺度生态水文耦 合作用理论阐释和定量刻画.

(2) 得益于现代观测技术的进步和上述微观尺度 生态水文学基础理论的发展, 在主要参数系统的精准 标定方面取得较大进展, 推动传统的基于物理机制的 植物冠层截留模型实现了在较小时间尺度上和大尺度 流域乃至全球尺度的较准确模拟. 在陆面实际蒸散发 量ET的精确模拟方面, 以Budyko能水平衡框架理论为 基础的针对不同生物气候区和生态类型的ET评估方法 发展仍然是能水量平衡分析角度的主要发展方向, 不 需要率定的非线性互补关系模型的发展为大尺度实际 蒸散发准确估算提供了有效途径; 将叶片叶绿素含量 与表征叶片光合能力的最大羧化能力指标间数量关系 与多层-双叶模型进行耦合嵌套，显著提升了较大空间 尺度上基于叶片气孔导度机理模型对ET的模拟精度, 


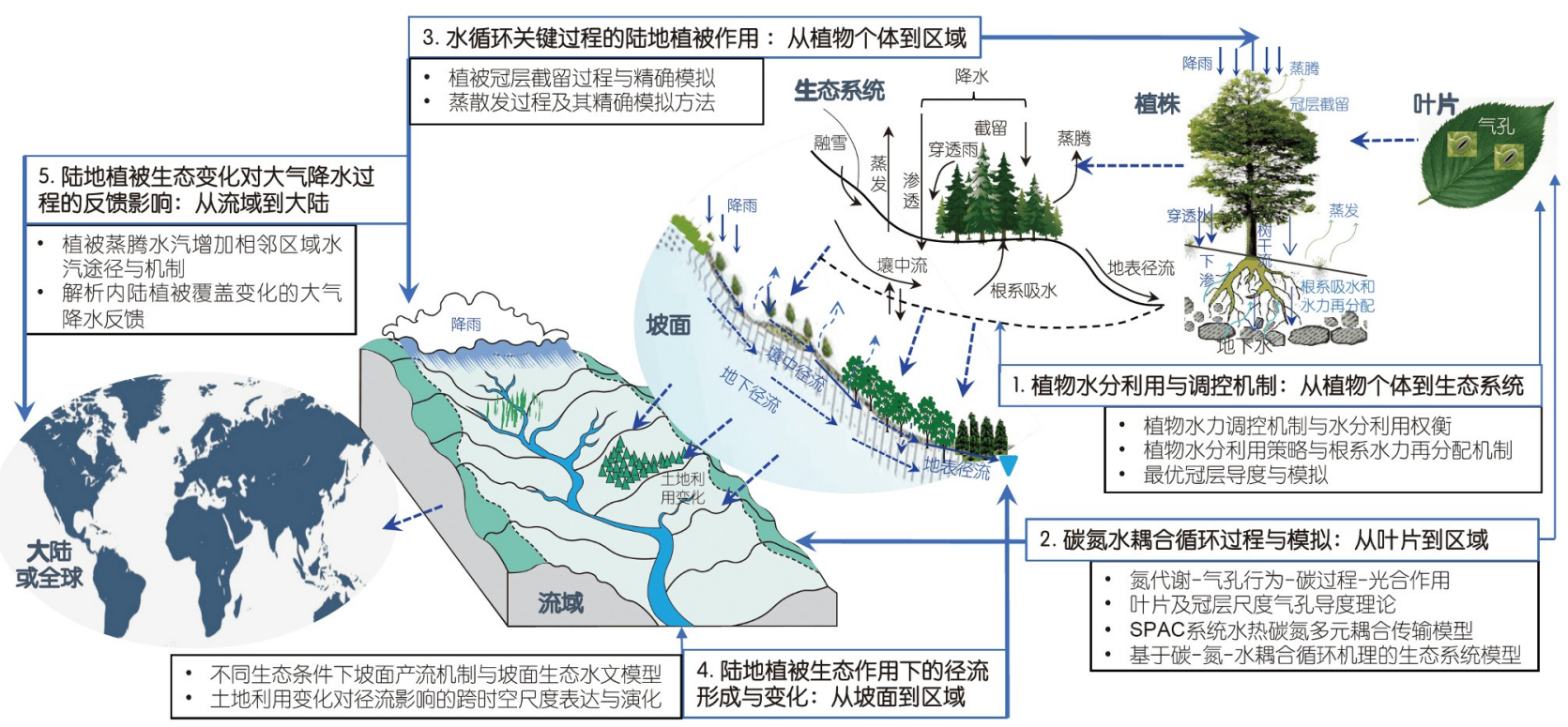

图 2 陆地植被生态水文过程研究的主要前沿进展内容与跨尺度递进关系

Figure 2 The main frontier advances and progressive relationship across scales in the study of terrestrial eco-hydrological processes

成为现阶段在水碳堣合分析角度刻画实际蒸散发最具 发展活力的方向.

（3）径流形成中的植被因素及其作用在不同尺度 上有不同表现. 在样地和坡面尺度上, 植被覆盖、结构 以及土地利用格局变化对地表降水-产流过程均产生 较大影响, 其中植被群落组成结构的影响可能超过植 被覆盖或土地利用格局变化的影响，同时还需要考虑 土壤性状和降水特征的复合作用; 流域尺度植被结 构、土地利用与覆盖变化对径流影响的争议可能与时 空尺度、水力连通性(包括前期土壤含水量阈值的时 空变异性)以及植被“蒸发效应”与“渗透效应”间权衡关 系变化等有关. 同时, 在大尺度流域或区域乃至大陆尺 度, 厘清土地利用与覆盖变化引起的蒸散发-大气水汽降水量的联结机制所产生的内循环降水量变化，对区 域可利用水量变化中植被因素的准确评估十分重要.

然而，在植被生态水文学领域取得上述进展的同 时, 也面临诸多挑战. 前面在梳理每个领域的主要进展 时，均列出了亟待解决的前沿问题，基于这些问题，将 未来主要关注的发展方向归纳为以下四方面.

（1）植物对水分的利用策略和应对变化环境的水 分调控机制, 是生态水文学理论体系的基础. 未来需要 进一步明确水分传输效率、水分传输安全性和机械支 撑构成的植物水分传输 “三角权衡关系”的有效性及其 支配的植物水分利用策略，并探索这一“三角权衡关
系”原理与根系水力再分配、生态水文分离以及等水 特性等理论的内在联系; 同时, 关注植物水分利用与调 控机理在个体-群落-生态系统间的多尺度关联机制.

（2）探索植被碳同化的边际水分消耗及其与光强 和水分状况等环境因子的多元耦合作用关系，并明晰 这一关系在不同植被及同一植被类型不同生长阶段的 变异规律, 确定具较高精度的碳同化边际水分消耗随 时空尺度变化的参数化方案; 同时, 寻求生态意义明确 并可跨尺度表达的生态系统碳水耦合参量及其定量描 述方法(如叶片叶绿素含量与表征叶片光合能力的最 大羧化能力定量关系)与冠层导度模型 (多层-双叶模 型)相结合, 发展基于冠层最优导度理论的跨尺度碳水 通量精准模拟方法，从而为提升对不同尺度陆面实际 蒸散发的模拟精度开辟更有效途径.

（3）水分的有效性及其动态变化如何并在多大程 度上制约生态系统的碳氮过程，是全球变化生态学亟 待解决的前沿瓶颈问题之一. 在全球变化背景下，降 水、温度以及土壤水分剧烈变化, 叠加氮沉降扰动, 形 成了极其复杂多变的碳氮水耦合循环格局与动态. 需 要系统明晰生态系统的水分有效性、氮供应和碳收益 间存在的复杂互馈作用关系及其临界条件；发展生态 系统碳氮过程与水循环过程全耦合的机理模型.

(4) 陆地水循环中的植被因素与作用机制仍然是 未来持续关注的重点问题，核心是径流形成与动态变 
化的生态因素甄别与定量刻画. 一方面, 需要系统性地 研判不同时空尺度上流域植被结构或土地利用与覆盖 变化对径流影响的主导因素, 并判识这些因素在跨尺 度上的传递作用与有效性; 另一方面, 基于不同生物气 候区流域尺度长期观测试验结果的比较与集成分析, 明确流域植被结构和格局变化，或是土地利用与覆盖
变化中植被“蒸发效应”与“渗透效应”间权衡关系改变 对径流过程的作用本质, 并掌握时间尺度上的动态演 变规律. 在更大空间尺度上, 还需要在掌握陆面植被结 构变化对陆-气耦合关系的影响基础上, 准确解析降水 量变化中来源于相关区域植被覆盖变化的大气反馈作 用及其贡献范围等.

\section{参考文献}

1 Newman B D, Wilcox B P, Archer S R, et al. Ecohydrology of water-limited environments: A scientific vision. Water Resour Res, 2006, 42: 376389

2 Xia J, Zuo Q T, Wang G X, et al. The Frontiers of Earth Science: Ecohydrology (in Chinese). Beijing: Science Press, 2020 [夏军, 左其亭, 王根绪, 等. 地球科学学科前沿丛书: 生态水文学. 北京: 科学出版社, 2020]

3 Zalewski M. Guidelines for integrated management of the watershed: Phytotechnology and ecohydrology. Freshw Manage, 2003, 85: 3-16

4 Eagleson P S. Ecohydrology: Darwinian Expression of Vegetation Form and Function. Cambridge: Cambridge University Press, 2002

5 Ivanov V Y, Bras R L, Vivoni E R. Vegetation-hydrology dynamics in complex terrain of semiarid areas: 1. A mechanistic approach to modeling dynamic feedbacks. Water Resour Res, 2015, 44: 173-175

6 Coenders-Gerrits A M J, van der Ent R J, Bogaard T A, et al. Uncertainties in transpiration estimates. Nature, 2014, 506: E1-E2

7 Baird A J, Wilby R L. Eco-hydrology: Plants and Water in Terrestrial and Aquatic Environment. New York: Routledge, 1999

8 Harper D, Zalewski M, Pacini N. Eco-hydrology: Processes, Models and Case Studies: An Approach to the Sustainable Management of Water Resources. Wallingford: CAB International, 2008

9 Medlyn B E, Duursma R A, De Kauwe M G, et al. The optimal stomatal response to atmospheric $\mathrm{CO}_{2}$ concentration: Alternative solutions, alternative interpretations. Agric For Meteorol, 2013, 182-183: 200-203

10 Linhoss A C, Siegert C M. Calibration reveals limitations in modeling rainfall interception at the storm scale. J Hydrol, 2020, $584:$ 124624

11 Fiener P, Auerswald K, Van Oost K. Spatio-temporal patterns in land use and management affecting surface runoff response of agricultural catchments-A review. Earth-Sci Rev, 2011, 106: 92-104

12 Samaniego L, Kumar R, Attinger S. Multiscale parameter regionalization of a grid-based hydrologic model at the mesoscale. Water Resour Res, 2010, 46: W05523

13 Vivoni E R. Spatial patterns, processes and predictions in ecohydrology: Integrating technologies to meet the challenge. Ecohydrology, 2012, 5: $235-241$

14 Barigah T S, Charrier O, Douris M, et al. Water stress-induced xylem hydraulic failure is a causal factor of tree mortality in beech and poplar. Ann Bot, 2013, 112: 1431-1437

15 Brown H R. The theory of the rise of sap in trees: Some historical and conceptual remarks. Phys Perspect, 2013, 15: 320-358

16 Hacke U G, Spicer R, Schreiber S G, et al. An ecophysiological and developmental perspective on variation in vessel diameter. Plant Cell Environ, 2017, 40: 831-845

17 Bittencourt P R, Pereira L, Oliveira R S. On xylem hydraulic efficiencies, wood space-use and the safety-efficiency tradeoff. New Phytol, 2016, 211: $1152-1155$

18 Cochard H, Venisse J S, Barigah T S, et al. Putative role of aquaporins in variable hydraulic conductance of leaves in response to light. Plant Physiol, 2007, 143: 122-133

19 Nardini A, Luglio J. Leaf hydraulic capacity and drought vulnerability: Possible trade-offs and correlations with climate across three major biomes. Funct Ecol, 2014, 28: 810-818

20 Chaves M M, Pereira J S, Maroco J, et al. How plants cope with water stress in the field? Photosynthesis and growth. Ann Bot, 2002, 89: 907-916

21 McDowell N G, Allen C D. Darcy's law predicts widespread forest mortality under climate warming. Nat Clim Chang, 2015, 5: 669-672

22 Choat B, Brodribb T J, Brodersen C R, et al. Triggers of tree mortality under drought. Nature, 2018, 558: 531-539

$23 \mathrm{Lu}$ R L, Du Y, Yan L M, et al. A methodological review on identification of tree mortality and their applications (in Chinese). Chin Sci Bull, 2019, 64: 2395-2409 [鲁苪伶, 杜芗, 晏黎明, 等. 森林树木死亡的判定方法及其应用综述. 科学通报, 2019, 64: 2395-2409]

24 Adams H D, Zeppel M J B, Anderegg W R L, et al. A multi-species synthesis of physiological mechanisms in drought-induced tree mortality. Nat Ecol Evol, 2017, 1: 1285-1291

25 Hochberg U, Rockwell F E, Holbrook N M, et al. Iso/Anisohydry: A plant-environment interaction rather than a simple hydraulic trait. Trends 
Plant Sci, 2018, 23: 112-120

26 McDowell N, Pockman W T, Allen C D, et al. Mechanisms of plant survival and mortality during drought: Why do some plants survive while others succumb to drought? New Phytol, 2008, 178: 719-739

27 Martínez-Vilalta J, Poyatos R, Aguadé D, et al. A new look at water transport regulation in plants. New Phytol, 2014, 204: 105-115

28 Brooks J R, Barnard H R, Coulombe R, et al. Ecohydrologic separation of water between trees and streams in a Mediterranean climate. Nat Geosci, 2010, 3: 100-104

29 Geris J, Tetzlaff D, McDonnell J, et al. Ecohydrological separation in wet, low energy northern environments? A preliminary assessment using different soil water extraction techniques. Hydrol Process, 2015, 29: 5139-5152

30 Geris J, Tetzlaff D, McDonnell J J, et al. Spatial and temporal patterns of soil water storage and vegetation water use in humid northern catchments. Sci Total Environ, 2017, 595: 486-493

31 Zhao P, Tang X, Zhao P, et al. Temporal partitioning of water between plants and hillslope flow in a subtropical climate. Catena, 2018, 165: 133144

32 Richards J H, Caldwell M M. Hydraulic lift: Substantial nocturnal water transport between soil layers by Artemisia tridentata roots. Oecologia, 1987, 73: 486-489

33 Burgess S S O, Adams M A, Turner N C, et al. The redistribution of soil water by tree root systems. Oecologia, 1998, 115: 306-311

34 Neumann R B, Cardon Z G. The magnitude of hydraulic redistribution by plant roots: A review and synthesis of empirical and modeling studies. New Phytol, 2012, 194: 337-352

35 Ryel R, Caldwell M, Yoder C, et al. Hydraulic redistribution in a stand of Artemisia tridentata: Evaluation of benefits to transpiration assessed with a simulation model. Oecologia, 2002, 130: 173-184

36 Amenu G G, Kumar P. A model for hydraulic redistribution incorporating coupled soil-root moisture transport. Hydrol Earth Syst Sci, 2008, 12: $55-74$

37 Siqueira M, Katul G, Porporato A. Onset of water stress, hysteresis in plant conductance, and hydraulic lift: Scaling soil water dynamics from millimeters to meters. Water Resour Res, 2008, 44: W01432

38 Schymanski S J, Sivapalan M, Roderick M L, et al. An optimality-based model of the coupled soil moisture and root dynamics. Hydrol Earth Syst Sci, 2008, 12: 913-932

39 Cowan I R, Farquhar G D. Stomatal function in relation to leaf metabolism and environment. In: Symposia of the Society for Experimental Biology, 1977, 31: 471-505

40 Katul G G, Palmroth S, Oren R. Leaf stomatal responses to vapour pressure deficit under current and $\mathrm{CO}_{2}$-enriched atmosphere explained by the economics of gas exchange. Plant Cell Environ, 2009, 32: 968-979

41 Medlyn B E, Duursma R A, Eamus D, et al. Reconciling the optimal and empirical approaches to modelling stomatal conductance. Glob Change Biol, 2011, 17: 2134-2144

42 Vico G, Manzoni S, Palmroth S, et al. A perspective on optimal leaf stomatal conductance under $\mathrm{CO}_{2}$ and light co-limitations. Agric For Meteorol, 2013, 182: 191-199

43 Kala J, Decker M, Exbrayat J F, et al. Influence of leaf area index prescriptions on simulations of heat, moisture, and carbon fluxes. J Hydrometeorol, 2014, 15: 489-503

44 De Kauwe M G, Kala J, Lin Y S, et al. A test of an optimal stomatal conductance scheme within the CABLE land surface model. Geosci Model Dev, 2015, 8: 431-452

45 Sellin A, Kupper P. Temperature, light and leaf hydraulic conductance of little-leaf linden (Tilia cordata) in a mixed forest canopy. Tree Physiol, 2007, 27: 679-688

46 Zhang S, Yang D, Yang Y, et al. Excessive afforestation and soil drying on China's Loess Plateau. J Geophys Res Biogeosci, 2018, 123: 923-935

47 Infante J M, Damesin C, Rambal S, et al. Modelling leaf gas exchange in holm-oak trees in southern Spain. Agric For Meteorol, 1999, 95: 203223

48 Scoffoni C, McKown A D, Rawls M, et al. Dynamics of leaf hydraulic conductance with water status: Quantification and analysis of species differences under steady state. J Exp Bot, 2012, 63: 643-658

49 Yu G R, Wang Q F. Eco-physiology of Photosynthesis, Transpiration and Water Use in Plants (in Chinese). Beijing: Science Press, 2010.584 [于 贵瑞, 王秋风. 植物光合、蒸腾与水分利用的生理生态学. 北京: 科学出版社, 2010. 584]

50 Yu G R, Gao Y, Wang Q F, et al. Discussion on the key processes of carbon-nitrogen-water coupling cycles and biological regulation mechanisms in terrestrial ecosystem (in Chinese). Chin J Eco-Agric, 2013, 21: 1-13 [于贵瑞, 高扬, 王秋风, 等. 陆地生态系统碳-氮-水循环的关键耦合过 程及其生物调控机制探讨. 中国生态农业学报, 2013, 21: 1-13]

51 Greaver T L, Clark C M, Compton J E, et al. Key ecological responses to nitrogen are altered by climate change. Nat Clim Chang, 2016, 6: 836843 
52 Ågren G I, Kattge J. Nitrogen productivity and allocation responses of 12 important tree species to increased $\mathrm{CO}_{2}$. Trees, 2017, 31: 617-621

53 Thomas R Q, Canham C D, Weathers K C, et al. Increased tree carbon storage in response to nitrogen deposition in the US. Nat Geosci, 2010, 3: $13-17$

54 Croft H, Chen J M, Luo X, et al. Leaf chlorophyll content as a proxy for leaf photosynthetic capacity. Glob Change Biol, 2017, 23: 3513-3524

55 Borken W, Matzner E. Reappraisal of drying and wetting effects on C and N mineralization and fluxes in soils. Glob Change Biol, 2009, 15: 808824

56 Cisneros J, Jiménez-Cisneros B E, Oki T, et al. IPCC, 2014: Climate Change 2014: Impacts, adaptation, and vulnerability. Part A: Global and sectoral aspects. In: Field C B, Barros V R, Dokken D J, et al., eds. Contribution of Working Group II to the Fifth Assessment Report of the Intergovernmental Panel on Climate Change. Cambridge: Cambridge University Press, 2014

57 Wu Q L, Lei Z D, Yang S X. The coupled iteration method in solving the water movement and heat transfer in SPAC (in Chinese). J Hydraul Eng, 1996, 2: 1-10 [吴擎龙, 雷志栋, 杨诗秀. 求解SPAC系统水热输移的耦合迭代计算方法. 水利学报, 1996, 2: 1-10]

58 Liang H, Hu K L, Li B G, et al. Coupled simulation of soil water-hear-carbon-nitrogen process and crop growth at soil-plant-atmosphere continuum system (in Chinese). Trans Chin Soc Agric Eng, 2014, 30: 54-66 [梁浩, 胡克林, 李保国, 等. 土壤-作物-大气系统水热碳氮过程耦 合模型构建. 农业工程学报, 2014, 30: 54-66]

59 Shi X, Batchelor W D, Liang H, et al. Determining optimal water and nitrogen management under different initial soil mineral nitrogen levels in northwest China based on a model approach. Agric Water Manage, 2020, 234: 106110

60 Xiang W H, Huang Z H, Yan W D, et al. Review on coupling of interactive functions between carbon and nitrogen cycles in forest ecosystems (in Chinese). Acta Ecol Sin, 2006, 26: 2365-2372 [项文化, 黄志宏, 间文德, 等. 森林生态系统碳氮循环功能耦合研究综述. 生态学报, 2006, 26: 2365-2372]

61 Zaehle S, Medlyn B E, De Kauwe M G, et al. Evaluation of 11 terrestrial carbon-nitrogen cycle models against observations from two temperate Free-Air $\mathrm{CO}_{2}$ Enrichment studies. New Phytol, 2014, 202: 803-822

62 Du Z G, Weng E S, Jiang L F, et al. Carbon-nitrogen coupling under three schemes of model representation: A traceability analysis. Geosci Model Dev, 2018, 11: 4399-4416

63 Zalewski M, Janauer G A, Jolankai G. Ecohydrology: A New Paradigm for the Sustainable Use of Aquatic Resources. Technical Documents in Hydrology, United Nations Educational Scientific and Cultural Organization, 1997

64 Hannah D M, Sadler J P, Wood P J. Hydroecology and ecohydrology: A potential route forward? Hydrol Process, 2007, 21: 3385-3390

65 Muzylo A, Llorens P, Valente F, et al. A review of rainfall interception modelling. J Hydrol, 2009, 370: 191-206

66 Linhoss A C, Siegert C M. A comparison of five forest interception models using global sensitivity and uncertainty analysis. J Hydrol, 2016, 538: $109-116$

67 Návar J. Modeling rainfall interception loss components of forests. J Hydrol, 2020, 584: 124449

68 Saito T, Matsuda H, Komatsu M, et al. Forest canopy interception loss exceeds wet canopy evaporation in Japanese cypress (Hinoki) and Japanese cedar (Sugi) plantations. J Hydrol, 2013, 507: 287-299

69 van Dijk A I J M, Gash J H, van Gorsel E, et al. Rainfall interception and the coupled surface water and energy balance. Agric For Meteorol, 2015, 214-215: 402-415

70 José N. Modeling rainfall interception components of forests: Extending drip equations. Agric For Meteorol, 2019, 279: 107704

71 Miralles D G, Gash J H, Holmes T R H, et al. Global canopy interception from satellite observations. J Geophys Res Atmos, 2010, 115: D16122

72 Jasechko S, Sharp Z D, Gibson J J, et al. Terrestrial water fluxes dominated by transpiration. Nature, 2013, 496: 347-350

73 Yu Q, Xie X Q, Sun S F, et al. Advances in simulation of plant photosynthetic productivity and canopy evapotranspiration (in Chinese). Acta Ecol Sin, 1999, 19: 744-753 [于强, 谢贤群, 孙菽芬, 等. 植物光合生产力与冠层蒸散模拟研究进展. 生态学报, 1999, 19: 744-753]

74 Dai Y J, Dickinson R E, Wang Y P. A two-big-leaf model for canopy temperature, photosynthesis, and stomatal conductance. J Clim, 2004, 17: 2281-2299

75 Shen S H, Zhang X S, Ouyang Z. An application of the two-leaf model in multilayer simulation for winter wheat canopy $\mathrm{CO}_{2}$ fluxes (in Chinese) Acta Meteorol Sin, 2011, 69: 819-829 [申双和, 张雪松, 欧阳竹. 双叶模型在冬小麦田冠层 $\mathrm{CO}_{2}$ 通量多层模拟中的应用. 气象学报, 2011, 69: 819-829]

76 Chen J M, Liu J, Cihlar J, et al. Daily canopy photosynthesis model through temporal and spatial scaling for remote sensing applications. Ecol Model, 1999, 124: 99-119

77 Kattge J, Knorr W, Raddatz T, et al. Quantifying photosynthetic capacity and its relationship to leaf nitrogen content for global-scale terrestrial biosphere models. Glob Change Biol, 2009, 15: 976-991

78 Franks P J, Berry J A, Lombardozzi D L, et al. Stomatal function across temporal and spatial scales: Deep-time trends, land-atmosphere coupling and global models. Plant Physiol, 2017, 174: 583-602

79 Houborg R, Cescatti A, Migliavacca M, et al. Satellite retrievals of leaf chlorophyll and photosynthetic capacity for improved modeling of GPP. 
Agric For Meteorol, 2013, 177: 10-23

80 Croft H, Chen J M, Froelich N J, et al. Seasonal controls of canopy chlorophyll content on forest carbon uptake: Implications for GPP modeling. J Geophys Res Biogeosci, 2015, 120: 1576-1586

81 Luo X Z, Croft H, Chen J M, et al. Incorporating leaf chlorophyll content into a two-leaf terrestrial biosphere model for estimating carbon and water fluxes at a forest site. Agric For Meteorol, 2018, 248: 156-168

82 Katahata S I, Naramoto M, Kakubari Y, et al. Seasonal changes in photosynthesis and nitrogen allocation in leaves of different ages in evergreen understory shrub Daphniphyllum humile. Trees, 2007, 21: 619-629

83 Wang S Q, Li Y, Ju W M, et al. Estimation of leaf photosynthetic capacity from leaf chlorophyll content and leaf age in a subtropical evergreen coniferous plantation. J Geophys Res-Biogeosci, 2020, doi: 10.1029/2019JG005020

84 Brutsaert W, Stricker H. An advection-aridity approach to estimate actual regional evapotranspiration. Water Resour Res, 1979, 15: 443-450

85 Morton F I. Operational estimates of areal evapotranspiration and their significance to the science and practice of hydrology. J Hydrol, 1983, 66: $1-76$

86 Granger R J, Gray D M. Evaporation from natural nonsaturated surfaces. J Hydrol, 1989, 111: 21-29

87 Han S J, Tian F Q, Hu H P. Positive or negative correlation between actual and potential evaporation? Evaluating using a nonlinear complementary relationship model. Water Resour Res, 2014, 50: 1322-1336

88 Brutsaert W. A generalized complementary principle with physical constraints for land-surface evaporation. Water Resour Res, 2015, 51: 80878093

89 Han S J, Tian F Q. Derivation of a sigmoid generalized complementary function for evaporation with physical constraints. Water Resour Res, 2018, 54: 5050-5068

90 Szilagyi J, Crago R, Qualls R. A calibration-free formulation of the complementary relationship of evaporation for continental-scale hydrology. J Geophys Res Atmos, 2017, 122: 264-278

91 Wang G X, Lin S, Hu Z Y, et al. Improving actual evapotranspiration estimation integrating energy consumption for ice phase change across the Tibetan Plateau. J Geophys Res-Atmos, 2020, 125: e2019JD031799

92 Brutsaert W, Li W, Takahashi A, et al. Nonlinear advection-aridity method for landscape evaporation and its application during the growing season in the southern Loess Plateau of the Yellow River basin. Water Resour Res, 2017, 53: 270-282

93 Hu Z, Wang G, Sun X, et al. Spatial-temporal patterns of evapotranspiration along an elevation gradient on Mount Gongga, Southwest China. Water Resour Res, 2018, 54: 4180-4192

$94 \mathrm{Gu} \mathrm{C}, \mathrm{Mu}$ X, Gao P, et al. Distinguishing the effects of vegetation restoration on runoff and sediment generation on simulated rainfall on the hillslopes of the Loess Plateau of China. Plant Soil, 2020, 447: 393-412

95 Bonnesoeur V, Locatelli B, Guariguata M R, et al. Impacts of forests and forestation on hydrological services in the Andes: A systematic review. For Ecol Manage, 2019, 433: 569-584

96 Mohammad A G, Adam M A. The impact of vegetative cover type on runoff and soil erosion under different land uses. Catena, 2010, 81: 97-103

97 Chen H, Zhang X, Abla M, et al. Effects of vegetation and rainfall types on surface runoff and soil erosion on steep slopes on the Loess Plateau, China. Catena, 2018, 170: 141-149

98 Merzer T. The effects of different vegetative cover on local hydrological balance of a semiarid afforestation. Master Dissertation. Beer Sheva: Jacob Blaustein Institute for Desert Research, Ben-Gurion University of the Negev, 2007

99 Maetens W, Poesen J, Vanmaercke M. How effective are soil conservation techniques in reducing plot runoff and soil loss in Europe and the Mediterranean? Earth-Sci Rev, 2012, 115: 21-36

100 Yang C X, Yao W Y, Xiao P Q, et al. Effects of vegetation cover structure on runoff and sediment yield and its regulation mechanism (in Chinese). J Hydr Eng, 2019, 50: 1078-1085 [杨春霞, 姚文艺, 肖培青, 等. 植被覆盖结构对坡面产流产沙的影响及调控机制分析. 水利学报, 2019, 50: 1078-1085]

101 Sidle R C, Gomi T, Loaiza Usuga J C, et al. Hydrogeomorphic processes and scaling issues in the continuum from soil pedons to catchments. Earth-Sci Rev, 2017, 175: 75-96

102 Chang S R, Huang S Y, Zha X, et al. Effects of rainfall intensity and vegetation coverage on runoff and sediment yield on red soil slope (in Chinese). J Soil Water Conserv, 2019, 33: 58-64 [常松涛, 黄少燕, 查轩, 等. 雨强和植被覆盖度对红壤坡面产流产沙的影响. 水土保持学报, 2019, 33: 58-64]

103 Nouwakpo S K, Weltz M A, Green C H M, et al. Combining 3D data and traditional soil erosion assessment techniques to study the effect of a vegetation cover gradient on hillslope runoff and soil erosion in a semi-arid catchment. Catena, 2018, 170: 129-140

104 Molina A, Vanacker V, Balthazar V, et al. Complex land cover change, water and sediment yield in a degraded Andean environment. J Hydrol, 2012, 472-473: 25-35

105 Chen H, Fleskens L, Baartman J, et al. Impacts of land use change and climatic effects on streamflow in the Chinese Loess Plateau: A meta- 
analysis. Sci Total Environ, 2020, 703: 134989

106 Calder I R, Smyle J, Aylward B. Debate over flood-proofing effects of planting forests. Nature, 2007, 450: 945

107 Zhou G, Wei X, Chen X, et al. Global pattern for the effect of climate and land cover on water yield. Nat Commun, 2015, 6: 5918

108 Elliott K J, Caldwell P V, Brantley S T, et al. Water yield following forest-grass-forest transitions. Hydrol Earth Syst Sci, 2017, 21: 981-997

109 Farley K A, Jobbagy E G, Jackson R B. Effects of afforestation on water yield: A global synthesis with implications for policy. Glob Change Biol, 2005, 11: 1565-1576

110 Jin Z, Guo L, Yu Y, et al. Storm runoff generation in headwater catchments on the Chinese Loess Plateau after long-term vegetation rehabilitation. Sci Total Environ, 2020, 748: 141375

111 Filoso S, Bezerra M O, Weiss K C B, et al. Impacts of forest restoration on water yield: A systematic review. PLoS One, 2017, 12: e0183210

112 Zhou G Y, Xia J, Zhou P, et al. Not vegetation itself but mis-revegetation reduces water resources (in Chinese). Sci China: Earth Sci, 2020, doi: 10.1360/N072020-0157 [周国逸, 夏军, 周平, 等. 不恰当的植被恢复导致水资源减少. 中国科学: 地球科学, 2020, doi: 10.1360/N0720200157]

113 Peña-Arancibia J L, Bruijnzeel L A, Mulligan M, et al. Forests as 'sponges' and 'pumps': Assessing the impact of deforestation on dry-season flows across the tropics. J Hydrol, 2019, 574: 946-963

114 Bracken L J, Wainwright J, Ali G A, et al. Concepts of hydrological connectivity: Research approaches, pathways and future agendas. Earth-Sci Rev, 2013, 119: 17-34

115 Spracklen D V, Arnold S R, Taylor C M. Observations of increased tropical rainfall preceded by air passage over forests. Nature, 2012, 489: 282285

116 Ellison D, Futter M N, Bishop K. On the forest cover-water yield debate: From demand- to supply-side thinking. Glob Change Biol, 2012, 18: 806-820

117 Sheil D, Murdiyarso D. How forests attract rain: An examination of a new hypothesis. BioScience, 2009, 59: 341-347

118 Molina R D, Salazar J F, Martínez J A, et al. Forest-induced exponential growth of precipitation along climatological wind streamlines over the amazon. J Geophys Res Atmos, 2019, 124: 2589-2599

119 Li Y, Piao S L, Li L Z X, et al. Divergent hydrological response to large-scale afforestation and vegetation greening in China. Sci Adv, 2018, 4: eaard4182

120 Zhang Q, Yang Z S, Hao X C, et al. Transition features of surface evapotranspiration responding to climate warming with spatial precipitationbased climate type in northern China (in Chinese). Chin Sci Bull, 2018, 63: 1035-1049 [张强, 杨泽粟, 郝小翠, 等. 北方蒸散对气候变暖响应随 降水类型转换特征. 科学通报, 2018, 63: 1035-1049]

121 van der Ent R J, Savenije H H G, Schaefli B, et al. Origin and fate of atmospheric moisture over continents. Water Resour Res, 2010, 46: 1-12 


\title{
Critical advances in understanding ecohydrological processes of terrestrial vegetation: From leaf to watershed scale
}

\author{
Genxu Wang ${ }^{1 *}$, Jun $\mathrm{Xia}^{2^{*}}$, Xiaoyan $\mathrm{Li}^{3}$, Da Yang ${ }^{4}$, Zhaoyong $\mathrm{Hu}^{1}$, Shouqin $\mathrm{Sun}^{1} \&$ Xiangyang $\mathrm{Sun}^{1}$ \\ ${ }^{1}$ State Key Laboratory of Hydraulics and Mountain River Engineering, College of Water Resource and Hydropower, Sichuan University, Chengdu \\ 610065, China; \\ ${ }^{2}$ State Key Laboratory of Water Resources and Hydropower Engineering Science, Wuhan University, Wuhan 430072, China; \\ ${ }^{3}$ School of Natural Resources, Faculty of Geographical Science, Beijing Normal University, Beijing 100875, China; \\ ${ }^{4}$ Xishuangbanna Tropical Botanical Garden, Chinese Academy of Sciences, Mengla 666303, China \\ * Corresponding authors, E-mail: wanggx@scu.edu.cn; xiajun666@whu.edu.cn
}

The study of ecohydrological processes within vegetated terrestrial ecosystems is one of the new frontiers in ecology, hydrology and global change studies, and one of the most theoretical areas in ecohydrology. In recent years, a great deal of research has been conducted on the interactions between vegetative ecological processes and hydrologic processes, ranging from plant cells scales to whole continent scale. These studies have made great progress in changing the way we think and approach both ecology and hydrology. However, from the perspective of Ecohydrology, a discipline that integrates Ecology and Hydrology, there is an urgent need to systematically summarize the progress of multi-scale theories and methods and to present new ideas on the theoretical frontiers in this emergent field. This review synthesizes and evaluates recent findings and future challenges in the science and modeling of ecohydrological progress in terrestrial vegetative systems including: (1) Plant water use and regulation; (2) coupled carbon-nitrogen-water cycle processes and modeling; (3) ecological effects of key processes in the hydrologic cycle; (4) influence of vegetation on the generation and alteration of runoff and overland flow; (5) feedback effects from changes in terrestrial vegetation ecological water cycle on localized and regional precipitation pattern. The main progress in these five aspects of ecohydrology at multi-scales and across-scales is systematically summarized, with special attention given to the development of process-based quantitative models. Based on our synthesis of progress in the ecohydrology of terrestrial vegetation systems, we identify the four primary avenues for future research. First, it is necessary to clarify the effectiveness of the "triangular trade-off relationship" among water transmission efficiency and safety, and those mechanisms underlying plant water use strategies are given that plant water use strategies and water regulation mechanisms under changing environmental conditions are the foundation of ecohydrological theory. Accordingly, an exploration of the internal associations among this "triangular trade-off relationship" and root hydraulics redistribution, ecohydrological separation, and isohydric characteristics will be needed. Special attention is needed for a better understanding of the multiscale mechanisms for plant water use and regulation at the individual-community scale. Second, in the light of marginal water consumption during vegetative carbon assimilation, we explore the multi-coupling relationships among marginal water consumption and environmental factors such as light intensity and water availability and variations in the relationship among various vegetation types and growth stages. The ecosystem carbon-water coupling parameters that have clear ecological significance across scales need to be determined and highlighted. It is also important to develop a cross-scale carbon and water flux modeling method based on the canopy optimal conductivity theory. Third, how and to what extent the water availability and its dynamic changes restrict ecosystem carbon and nitrogen process is one of the frontier bottlenecks that need to be resolved to advance global change ecology. It is necessary to systematically clarify the complex interactions and threshold conditions between the water availability, nitrogen supply, and carbon benefits of the ecosystem. Development of mechanism models for the full coupling of ecosystem carbon and nitrogen cycling and hydrologic cycle processes are also crucial. Fourth, the vegetation factors and mechanisms in the terrestrial water cycle remain key issues for continued attention in the future. The core issue is the identification and quantitative description of ecological factors in the formation and dynamic changes in runoff. On a larger spatial scale, it is also vital to accurately analyze the atmospheric feedback and contribution range of changes in precipitation from the vegetation cover changes in the relevant regions based on the understanding of the impact of land surface vegetation structure changes on the land-atmosphere coupling relationship.

ecohydrological process of terrestrial vegetation, multi-scales, plant water use strategies and regulation, carbonnitrogen-water coupling

doi: 10.1360/TB-2020-1339 